\title{
Exact analytical modeling of magnetic vector potential in surface inset permanent magnet DC machines considering magnet segmentation
}

\begin{abstract}
Ali Jabbari*
Surface inset permanent magnet DC machine can be used as an alternative in automation systems due to their high efficiency and robustness. Magnet segmentation is a common technique in order to mitigate pulsating torque components in permanent magnet machines. An accurate computation of air-gap magnetic field distribution is necessary in order to calculate machine performance. An exact analytical method for magnetic vector potential calculation in surface inset permanent magnet machines considering magnet segmentation has been proposed in this paper. The analytical method is based on the resolution of Laplace and Poisson equations as well as Maxwell equation in polar coordinate by using sub-domain method. One of the main contributions of the paper is to derive an expression for the magnetic vector potential in the segmented PM region by using hyperbolic functions. The developed method is applied on the performance computation of two prototype surface inset magnet segmented motors with open circuit and on load conditions. The results of these models are validated through FEM method.
\end{abstract}

K e y w ord s: analytical modeling, surface inset PM motor, magnet segmentation, sub-domain method, FEM

\section{Introduction}

Permanent magnet motors are interested in industrial applications due to their high efficiency and power density $[1,2]$. An accurate prediction of air-gap magnetic field distribution is necessary in order to calculate machine performance. A variety of techniques including analytical and numerical methods has been conducted to evaluate the magnetic vector potential in electrical machines. Numerical methods like finite element method (FEM) give accurate results and are time consuming specially in first step of design stage. Analytical methods including conformal mapping [3]-[6], Magnetic Equivalent Circuit (MEC) [7-9], sub-domain model [10-26] and slot relative permeance calculation [27-30] are reported to model electrical machines and are useful in first step of performance evaluation and design optimization stage. The sub-domain model is more accurate than the other analytical models [7]. This method is developed based on solution of Laplace and Poisson equations in different regions by applying boundary conditions for electrical machines [10-26].

To author's knowledge, a few analytical models are presented to calculate magnetic vector potential in surface inset permanent magnet motors [27-29]. No references in the literature addressing the issue of an analytical model for surface inset magnet segmented machines were found.
The focus of this paper is to develop an analytical model based on resolution of Laplace and Poisson equations in surface inset permanent magnet machines by using the sub-domain method considering magnet segmentation and slotting effects. It is shown that the developed model can effectively estimate magnetic vector potential, magnetic flux density, cogging torque and electromagnetic torque. This model is applied on the performance calculation of two prototypes, ie a 2 segmented 5S-2P PM motor and a 3 segmented 5S-2P PM motor. It is shown that the results of analytical model are in close agreement with the results of FEM.

\section{Problem statement}

The geometrical representation of the investigated permanent magnet motor with magnet segmented outer rotor layout is shown in Fig. 1. The machine model is divided into three sub-domains including the armature slots region (domain $j$ ) which has $Q_{1}$ slots, the air-gap region (domain $I$ ) and the permanent magnet region (domain $k)$ which has $Q_{2}$ magnets. The machine parameters including the stator yoke radius $R_{1}$, the stator surface radius $R_{2}$, the rotor surface radius $R_{3}$, and the rotor slot radius $R_{4}$.

\footnotetext{
* Department of Mechanical Engineering, Faculty of Engineering, Arak University, Arak, 38156-8-8849, Iran, a-jabbari@araku.ac.ir
} 


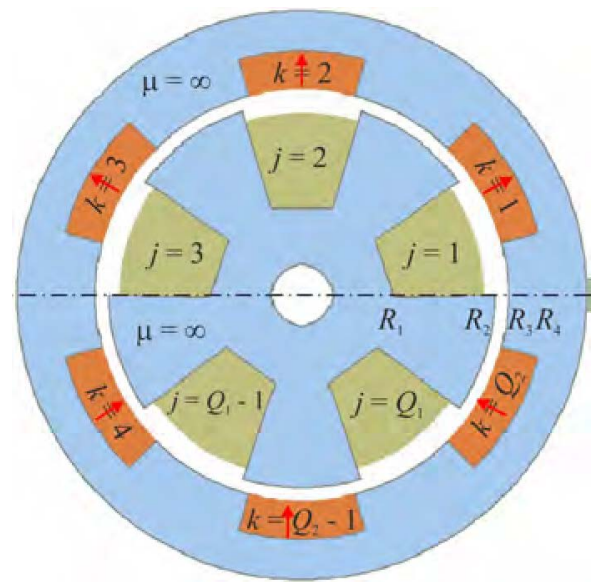

Fig. 1. Schematic representation of a surface inset magnet segmented motor

The angular position of the $j$-th armature slot and $k$-th stator permanent magnet are defined as

$$
\begin{aligned}
& \theta_{j}=-\frac{\alpha}{2}+\frac{2 j \pi}{Q_{1}} \text { with } 1 \leq j \leq Q_{1}, \\
& \theta_{k}=-\frac{\gamma}{2}+\frac{2 k \pi}{Q_{2}} \text { with } 1 \leq k \leq Q_{2} .
\end{aligned}
$$

\section{Magnetic vector potential calculation}

General solution of Laplace or Poisson equation in each sub-domain is developed in this section. The Laplace equation can be described in polar form as

$$
\frac{\partial^{2} A}{\partial r^{2}}+\frac{1}{r} \frac{\partial A}{\partial r}+\frac{1}{r^{2}} \frac{\partial^{2} A}{\partial \theta^{2}}=0 \quad \text { for } \quad\left\{\begin{aligned}
R_{1} & \leq r \leq R_{2} \\
\theta_{1} & \leq \theta \leq \theta_{2} .
\end{aligned}\right.
$$

Replacing $r$ by $R_{1} e^{-t}$, one obtains

$$
\frac{\partial^{2} A}{\partial t^{2}}+\frac{\partial^{2} A}{\partial \theta^{2}}=0 \text { for }\left\{\begin{array}{c}
\ln \frac{R_{1}}{R_{2}} \leq t \leq 0 \\
\theta_{1} \leq \theta \leq \theta_{2}
\end{array}\right.
$$

3.1 Magnetic vector potential in the armature slot subdomain (Region $j$ )

The Poisson equation in the armature slot sub-domain is given by

$$
\frac{\partial^{2} A_{j}}{\partial t^{2}}+\frac{\partial^{2} A_{j}}{\partial \theta^{2}}=-\mu_{0} J \quad \text { for } \quad\left\{\begin{array}{c}
t_{1} \leq t \leq t_{2}, \\
\theta_{j} \leq \theta \leq \theta_{j}+\alpha
\end{array}\right.
$$

where $t_{1}=\ln \left(R_{1} / R_{2}\right)$ and $t_{2}=0$.

Neumann boundary conditions at the bottom and at each side of the slot are obtained as

$$
\begin{gathered}
\left.\frac{\partial A_{j}}{\partial \theta}\right|_{\theta=\theta_{j}}=0 \quad \text { and }\left.\quad \frac{\partial A_{j}}{\partial \theta}\right|_{\theta=\theta_{j}+\alpha}=0, \\
\left.\frac{\partial A_{j}}{\partial t}\right|_{t=t_{2}}=0 .
\end{gathered}
$$

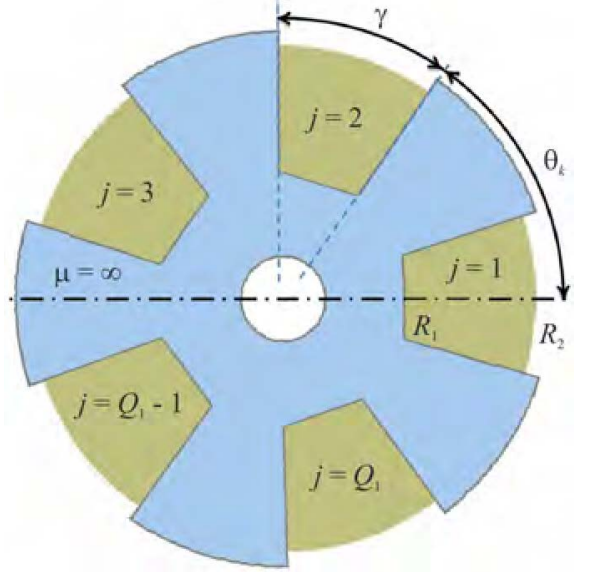

Fig. 2. Armature slot region (domain $j$ ) with its boundaries

The general solution of (5) using the separation of variables method is given by

$$
\begin{aligned}
A_{j}(t, \theta)=a_{0}^{j}- & \frac{1}{2} \mu_{0} J_{i}\left(e^{-t_{2}} t+\frac{1}{2} e^{-2 t+t_{2}}\right)+ \\
& \sum_{h=1}^{\infty} \frac{\cosh \frac{h \pi}{\alpha}\left(t-t_{2}\right)}{\cosh \frac{h \pi}{\alpha}\left(t_{1}-t_{2}\right)} a_{h}^{j} \cos \frac{h \pi}{\alpha}\left(\theta-\theta_{j}\right)
\end{aligned}
$$

where $h$ is a positive integer and the coefficients $a_{0}^{j}$ and $a_{h}^{j}$ are determined based on the continuity and interface conditions.

The continuity of the magnetic vector potential between the sub-domain $j$ and the region $I$ leads to

$$
A_{j}\left(t_{1}, \theta\right)=A_{I}\left(t_{4}, \theta\right) \quad \text { for } \quad \theta_{j} \leq \theta \leq \theta_{j}+\alpha
$$

Interface condition (9) gives

$$
\begin{gathered}
a_{0}^{j}=\frac{1}{2} \mu_{0} J_{i}\left(e^{-t_{2}} t+\frac{1}{2} e^{-2 t+t_{2}}\right)+\frac{1}{\alpha} \int_{\theta_{j}}^{\theta_{j}+\alpha} A_{I}\left(t_{4}, \theta\right) \mathrm{d} \theta, \\
a_{h}^{j}=\frac{2}{\alpha} \int_{\theta_{j}}^{\theta_{j}+\alpha} A_{I}\left(t_{4}, \theta\right) \cdot \cos \frac{h \pi}{\alpha}\left(\theta-\theta_{j}\right) \mathrm{d} \theta .
\end{gathered}
$$

3.2 Magnetic vector potential in the air-gap sub-domain (Region I)

The Laplace equation in the air-gap sub-domain is given by

$$
\frac{\partial^{2} A_{I}}{\partial t^{2}}+\frac{\partial^{2} A_{I}}{\partial \theta^{2}}=0 \quad \text { for } \quad\left\{\begin{array}{c}
t_{3} \leq t \leq t_{4} \\
0 \leq \theta \leq 2 \pi
\end{array}\right.
$$

where $t_{3}=\ln \left(R_{2} / R_{3}\right), t_{4}=0$.

The general solution of (12) considering periodicity boundary conditions is obtained as

$A_{I}(t, \theta)=$

$$
\begin{aligned}
& \sum_{n=1}^{\infty} \frac{1}{n}\left(\frac{\cosh n\left(t-t_{4}\right)}{\sinh n\left(t_{3}-t_{4}\right)} a_{n}^{I}+\frac{\cosh n\left(t-t_{3}\right)}{\sinh n\left(t_{4}-t_{3}\right)} b_{n}^{I}\right) \cos n \theta+ \\
& \text { (7) } \sum_{n=1}^{\infty} \frac{1}{n}\left(\frac{\cosh n\left(t-t_{4}\right)}{\sinh n\left(t_{3}-t_{4}\right)} c_{n}^{I}+\frac{\cosh n\left(t-t_{3}\right)}{\sinh n\left(t_{4}-t_{3}\right)} d_{n}^{I}\right) \sin n \theta .
\end{aligned}
$$


The coefficients $a_{n}^{I}, b_{n}^{I}, c_{n}^{I}$ and $d_{n}^{I}$ are determined considering the continuity of magnetic vector potential between the internal air-gap sub-domain $I$ and the region $j$ and $k$ using a Fourier series expansion of interface condition (14) and (15) over the air-gap interval.

The continuity of the magnetic vector potential between the internal air-gap sub-domain $I$ and the regions $j$ and $k$ leads to

$$
\begin{aligned}
& \left.\frac{\partial A_{I}}{\partial t}\right|_{t=t_{3}}=h(\theta)= \begin{cases}\left.\frac{\partial A_{k}}{\partial t}\right|_{t=t_{6}} & \text { for } \theta_{k} \leq \theta \leq \theta_{k}+\gamma, \\
0 & \text { elsewhere, }\end{cases} \\
& \left.\frac{\partial A_{I}}{\partial t}\right|_{t=t_{4}}=g(\theta)= \begin{cases}\left.\frac{\partial A_{j}}{\partial t}\right|_{t=t_{1}} & \text { for } \theta_{j} \leq \theta \leq \theta_{j}+\alpha, \\
0 & \text { elsewhere. }\end{cases}
\end{aligned}
$$

Interface condition (14) gives

$$
\begin{aligned}
& a_{n}^{I}=\frac{2}{2 \pi} \int_{\theta_{k}}^{\theta_{k}+\gamma} h(\theta) \cos n \theta \mathrm{d} \theta, \\
& c_{n}^{I}=\frac{2}{2 \pi} \int_{\theta_{k}}^{\theta_{k}+\gamma} h(\theta) \sin n \theta \mathrm{d} \theta .
\end{aligned}
$$

Interface condition (15) gives

$$
\begin{aligned}
& b_{n}^{I}=\frac{2}{2 \pi} \int_{\theta_{j}}^{\theta_{j}+\alpha} g(\theta) \cos n \theta \mathrm{d} \theta, \\
& d_{n}^{I}=\frac{2}{2 \pi} \int_{\theta_{j}}^{\theta_{j}+\alpha} g(\theta) \sin n \theta \mathrm{d} \theta .
\end{aligned}
$$

3.3 Magnetic vector potential in the stator permanent magnet sub-domain (Region $k$ )

The Poisson equation in the stator permanent magnet sub-domain is given by

$$
\begin{aligned}
\frac{\partial^{2} A_{k}}{\partial t^{2}}+\frac{\partial^{2} A_{k}}{\partial \theta^{2}}= & -\frac{\mu_{0} e^{t}}{R_{3}}\left(M_{\theta k}-\frac{\partial M_{r k}}{\partial \theta}\right) \\
& \text { for } t_{5} \leq t \leq t_{6}, \theta_{k} \leq \theta \leq \theta_{k}+\gamma
\end{aligned}
$$

where $t_{5}=\ln \left(R_{3} / R_{4}\right)$ and $t_{6}=0$.

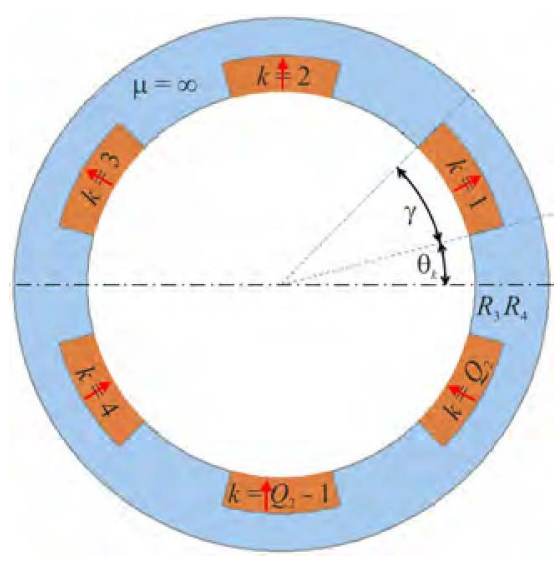

Fig. 3. Permanent magnet region (domain $k$ ) with its boundaries
The radial and tangential components of radial magnetization for inset design can be expressed as

$$
\begin{gathered}
M_{r k}=(-1)^{\left[\frac{k}{s+0.5}\right]} \frac{B_{r}}{\mu_{0}} \quad \text { with } k=1,2, \ldots, Q_{2}, \\
M_{\theta k}=0
\end{gathered}
$$

where $p$ is number of pole pairs and $s$ is number of magnet segmentations.

Neumann boundary conditions at the bottom and both sides of the permanent magnet slot are obtained as

$$
\begin{gathered}
\left.\frac{\partial A_{I}}{\partial \theta}\right|_{\theta=\theta_{k}}=f(t)=R_{3} e^{-t}(-1)^{\left[\frac{k}{s+0.5}\right]} B_{r}, \\
\left.\frac{\partial A_{I}}{\partial \theta}\right|_{\theta=\theta_{k}+\gamma}=f(t)=R_{3} e^{-t}(-1)^{\left[\frac{k}{s+0.5}\right]} B_{r}, \\
\left.\frac{\partial A_{I}}{\partial t}\right|_{t=t_{5}}=0 .
\end{gathered}
$$

The general solution of (20) is

$$
A_{k}(t, \theta)=a_{0}^{k}+R_{3}\left(e^{-\left(t-t_{5}\right)}+t\right)(-1)^{\left[\frac{k}{s+0.5}\right]} B_{r}\left(\theta-\theta_{k}-\frac{\gamma}{2}\right),
$$

$$
X_{h}^{k}= \begin{cases}\frac{4(-1)^{\left[\frac{k}{s+0.5}\right]_{B_{r}}}}{\gamma z^{2}\left(z^{2}-1\right)} & \text { if } h=1,3,5, \ldots \\ 0 & \text { if } h=2,4,6, \ldots\end{cases}
$$

where $z=h \pi / \gamma, h$ is a positive integer and the coefficients $a_{0}^{k}$ and $a_{h}^{k}$ are determined based on the continuity and interface conditions.

The continuity of the magnetic vector potential between the sub-domain $k$ and the regions $I$ leads to

$$
A_{k}\left(t_{6}, \theta\right)=A_{I}\left(t_{3}, \theta\right) \quad \text { for } \theta_{k} \leq \theta \leq \theta_{k}+\gamma .
$$

Interface condition (28) gives

$$
\begin{gathered}
a_{0}^{k}=R_{2}(-1)^{\left[\frac{k}{s+0.5}\right]} B_{r}\left(\theta-\theta_{k}-\frac{\gamma}{2}\right)+\frac{1}{\gamma} \int_{\theta_{k}}^{\theta_{k}+\gamma} A_{I}\left(t_{3}, \theta\right) \mathrm{d} \theta \\
a_{h}^{k}=\frac{2}{\gamma} \int_{\theta_{k}}^{\theta_{k}+\gamma} A_{I}\left(t_{3}, \theta\right) \cos z\left(\theta-\theta_{k}\right) \mathrm{d} \theta
\end{gathered}
$$

\section{Performance calculation and model evaluation}

\subsection{Performance computation}

The electromagnetic torque is obtained using the Maxwell stress tensor and expressed as

$$
T_{e}=\frac{L_{s}}{\mu_{0}} \int_{0}^{2 \pi} B I_{r}\left(t_{e}, \theta\right) B I_{\theta}\left(t_{e}, \theta\right) \mathrm{d} \theta
$$

where $L_{s}$ is the axial length of the motor and

$$
t_{e}=\ln \frac{R_{2}}{R_{e}}, \quad R_{e}=\left(R_{2}+R_{3}\right) / 2 .
$$


Table 1. Parameters of the investigated $5 \mathrm{~s}-2 \mathrm{p}$ motors

\begin{tabular}{clcc}
\hline Symbol & \multicolumn{1}{c}{ Quantity } & $S=2$ & $S=3$ \\
\hline$R_{1}$ & Inner radius of the armature slot & $10 \mathrm{~mm}$ & $10 \mathrm{~mm}$ \\
$R_{2}$ & Outer radius of the armature slot & $16.4 \mathrm{~mm}$ & $16.4 \mathrm{~mm}$ \\
$R_{3}$ & Inner radius of the stator PMs & $17.4 \mathrm{~mm}$ & $17.4 \mathrm{~mm}$ \\
$R_{4}$ & Outer radius of the stator PMs & $20.5 \mathrm{~mm}$ & $20.5 \mathrm{~mm}$ \\
$\theta_{j}$ & Angular position of the first slot & 17.5 & 17.5 \\
$\theta_{k}$ & Angular position of the first PM & 15 & 15 \\
$\alpha$ & Slot opening angle & 37 & 37 \\
$\gamma$ & PMs opening angle & 60 & 30 \\
$p$ & Pole pairs-number & 12 & 12 \\
$B_{r}$ & Remanence of the PMs & $0.7 \mathrm{~T}$ & $0.7 \mathrm{~T}$ \\
$L_{s}$ & Axial length & $35 \mathrm{~mm}$ & $35 \mathrm{~mm}$ \\
\hline
\end{tabular}

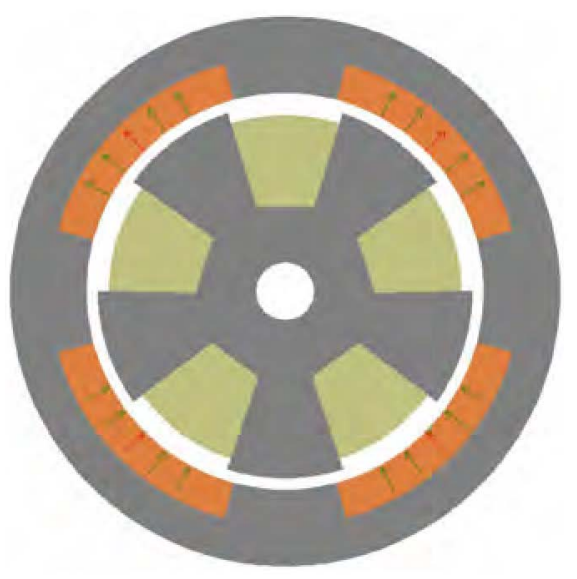

(a)

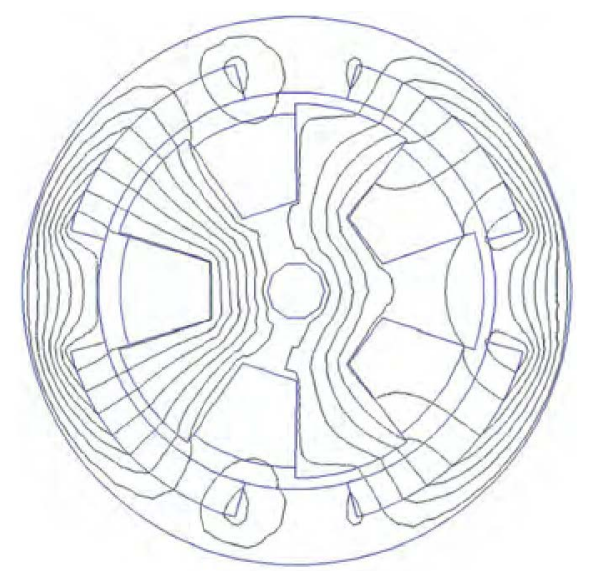

(b)

Fig. 4. Two segmented surface inset PM motor: (a) - the schematic representation, (b) - magnetic flux distribution

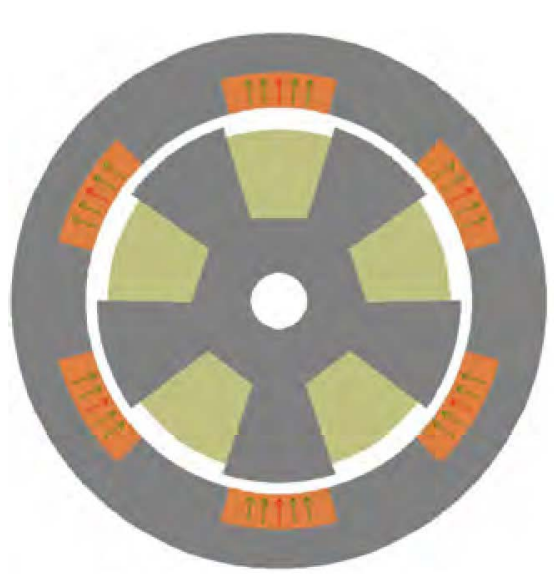

(a)

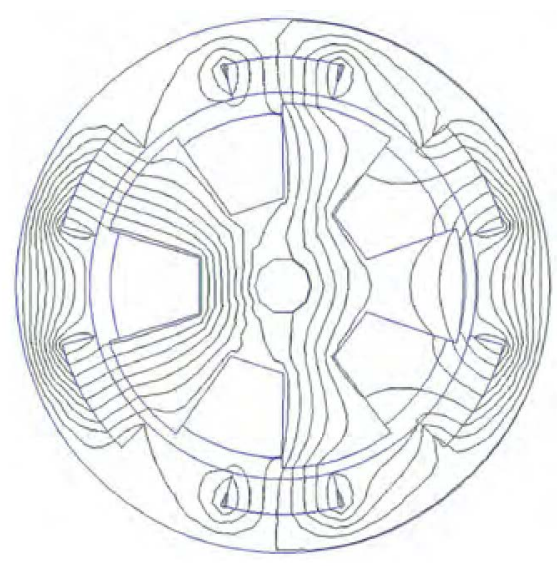

(b)

Fig. 5. Three segmented surface inset PM motor: (a) - the schematic representation, (b) - magnetic flux distribution

\subsection{Model evaluation}

In this section, the proposed analytical model is used to study the open circuit and on load magnetic flux density, open circuit cogging torque and on load electromagnetic torque of two prototype motors. The results of an- alytical method are then verified by the results of finite element method. The motors parameters are given in Table 1. The schematic representation model of two investigated $5 \mathrm{~S}-2 \mathrm{P}$ surface inset PM motors and their corresponding magnetic flux distribution obtained by FEA are shown in Fig. 4 and Fig. 5, respectively. 
Radial flux density $(\mathrm{T})$

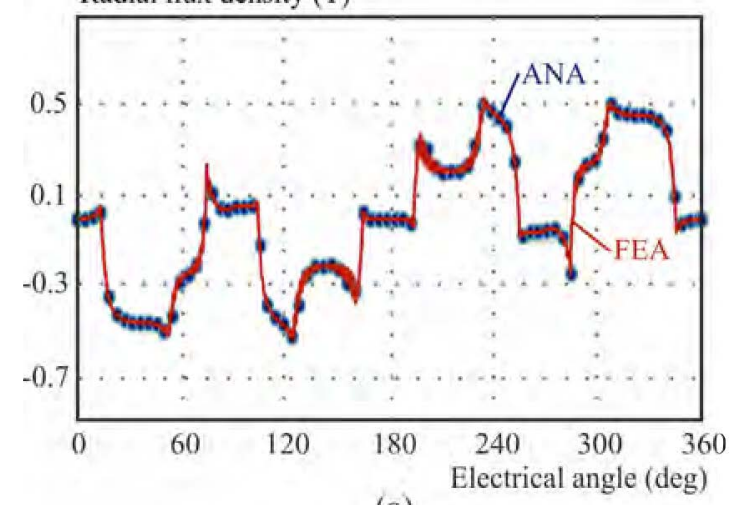

(a)

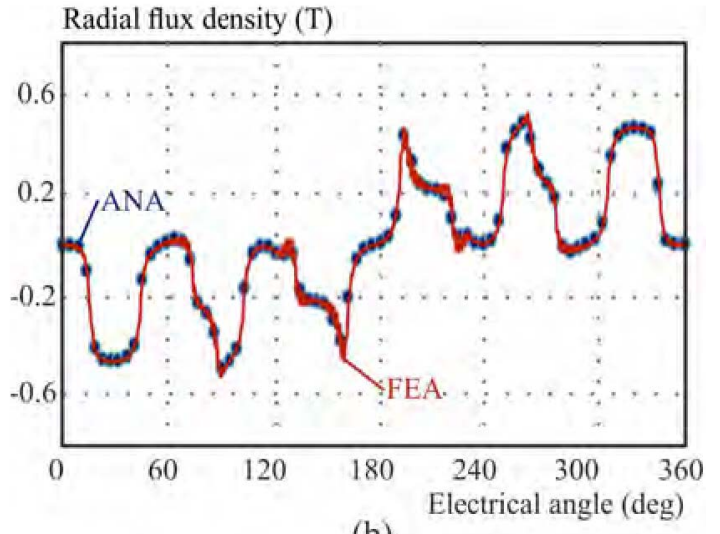

(b)

Fig. 6. No load analytical and numerical comparison of radial flux density for: (a) -2 segment pm motor, (b) - 3 segment PM motor

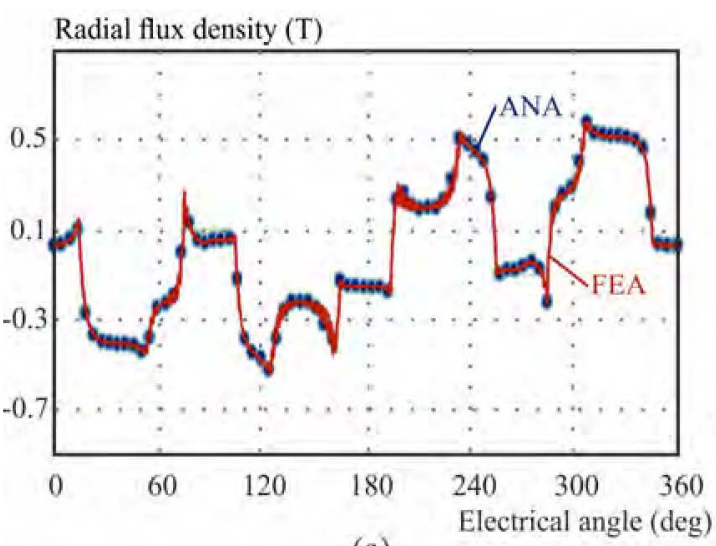

(a)

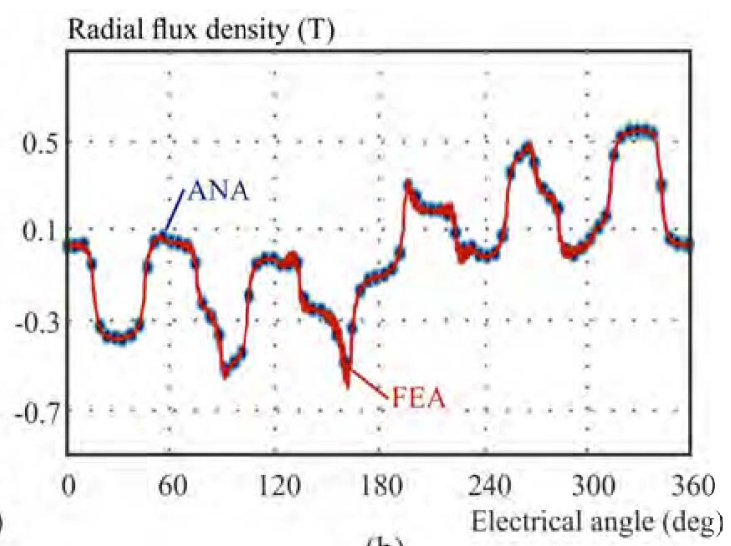

(b)

Fig. 7. On load analytical and numerical comparison of radial flux density for: (a) -2 segment pm motor, (b) -3 segment PM motor

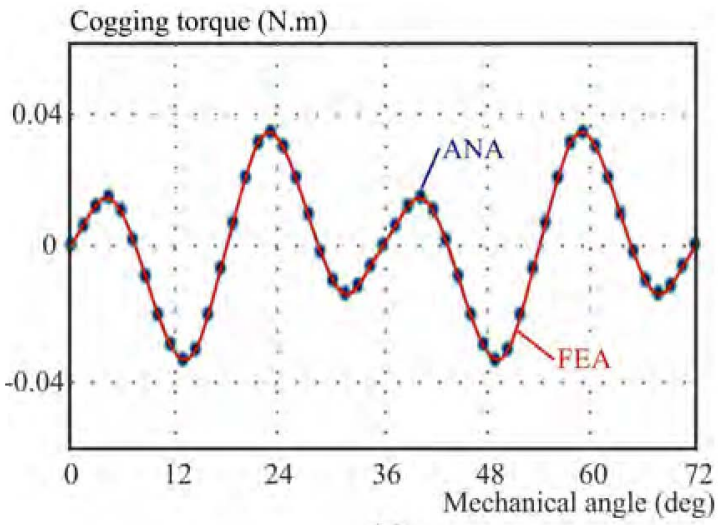

(a)

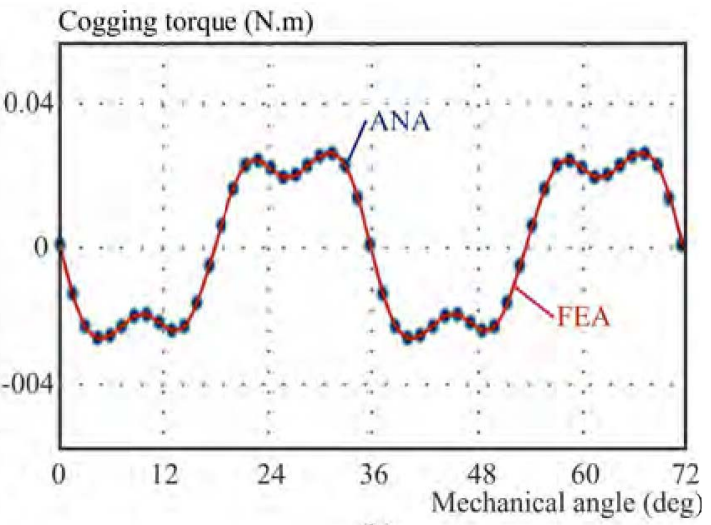

(b)

Fig. 8. Open circuit analytical and numerical comparison of cogging torque for: (a) -2 segment pm motor, (b) -3 segment PM motor

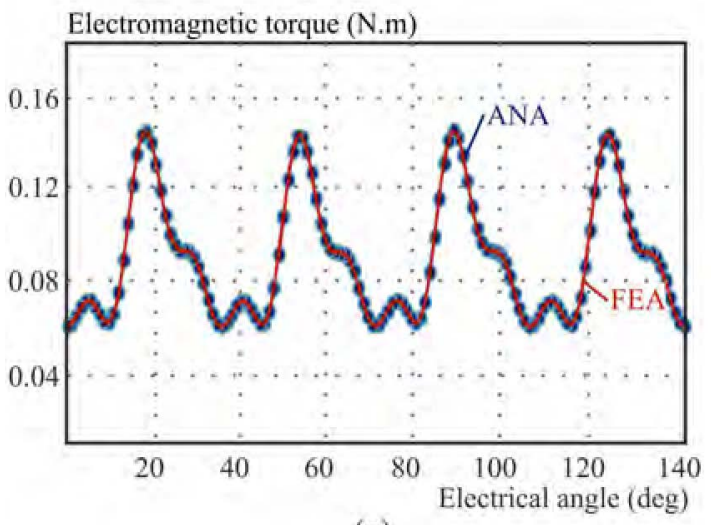

(a)

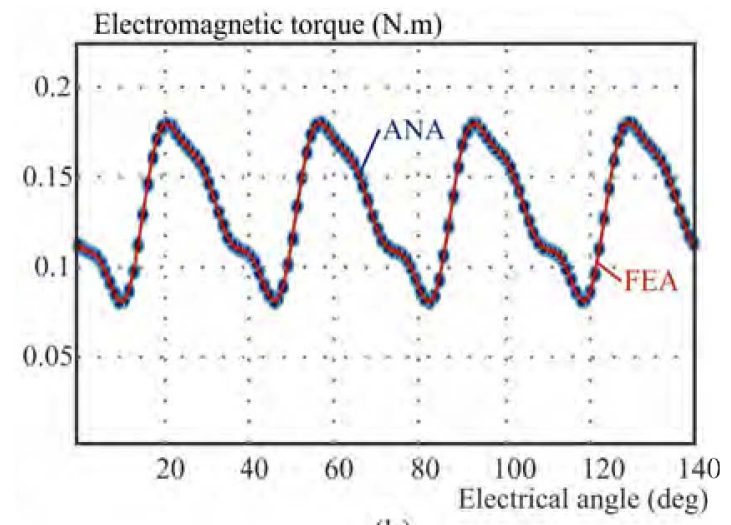

(b)

Fig. 9. On load analytical and numerical comparison of electromagnetic torque for: (a) -2 segment pm motor, (b) -3 segment PM motor 
2D finite element method is applied on performance calculation of the two magnet segmented and three magnet segmented surface inset permanent magnet motors. A comparison of open circuit and on load analytical and numerical results of radial flux density, cogging torque and electromagnetic torque in the investigated motors are shown in Fig. 6, Fig. 7, Fig. 8 and Fig. 9, respectively.

\section{Conclusion}

An exact analytical model for performance prediction in surface inset permanent magnet machines considering slotting effects and magnet segmentation has been developed in this paper. Fourier analysis method based on subdomain method is applied to derive analytical expressions for calculation of magnetic vector potential, magnetic flux density, cogging torque and electromagnetic torque in surface inset permanent magnet machines. This model is applied for performance computation of two prototype motors and the results of proposed model are verified thanks to FEM results.

\section{REFERENCES}

[1] A. Jabbari, M. Shakeri and S. A. Nabavi Naki, "Pole Shape Optimization of Permanent Magnet Synchronous Motors Using the Reduced Basis Technique", Iranian J. of Electrical and Electronic Engineering, 2010, vol. 6, no. 1, pp. 48-55.

[2] A. Jabbari, M. Shakeri and A. S. Gholamian, "Rotor Pole Shape Optimization of Permanent Magnet Brushless DC Motors Using the Reduced Basis Technique", Advances Electrical and Computer Engineering, 2009, vol. 9, no. 2, pp. 75-81.

[3] Z. Q. Zhu, D. Howe, "Instantaneous Magnetic Field Distribution Brushless Permanent Magnet DC Motors, III. Effect of Stator Slotting", IEEE Trans. on Mag. Jan 1993, vol. 29, no. 1, pp. $143-151$.

[4] M. Markovic, M. Jufer and Y. Perriard, "Reducing the Cogging Torque Brushless DC Motors by Using Conformal Mappings", IEEE Trans on Mag. Mar 2004, vol. 40, no. 2, pp. 451-455.

[5] D. Zarko, D. Ban and T. A. Lipo, "Analytical Calculation of Magnetic Field Distribution the Slotted Air Gap of a Surface Permanent-Magnet Motor Using Complex Relative Air-Gap Permeance", IEEE Trans. on Mag. July 2006, vol. 42, no. 7, pp. $1828-1837$.

[6] K. Boughrara, D. Zarko, R. Ibtiouen, O. Touhami and A. Rezzoug, "Magnetic Field Analysis of Inset and Surface-Mounted Permanent-Magnet Synchronous Motors Using Schwarz-Christoffel Transformation", IEEE Trans. on Mag. Aug 2009, vol. 45, no. 8, pp. 3166-3178.

[7] E. Ilhan, B. L. Gysen, J. J. Paulides and E. A. Lomonova, "Analytical Hybrid Model for Flux Switching Permanent Magnet Machines", IEEE Trans. on Mag. June 2010, vol. 46, no. 6, pp. $1762-1765$.

[8] Y. Tang, T. E. Motoasca, J. J. Paulides and E. A. Lomonova, "Analytical Modeling of Flux-Switching Machines Using Variable Global Reluctance Networks", Electrical Machines ICEM, XXth International Conference on, 2012, Sep 2, pp. 2792-2798.

[9] W. Hua, G. Zhang, M. Cheng and J. Dong, "Electromagnetic Performance Analysis of Hybrid-Excited Flux-Switching Machines by a Nonlinear Magnetic Network Model", IEEE Trans. on Mag. Oct 2011, vol. 47, no. 10, pp. 3216-3219.
[10] G. Qishan and G. Hongzhan, "Effect of Slotting PM Electric Machines", Electric machines and power systems, Jan 1985, vol. 10, no. 4 , pp. $273-284$.

11] A. Jabbari, "2D Analytical Modeling of Magnetic Vector Potential Surface Mounted and Surface Inset Permanent Magnet Machines", Iranian J. of Electrical and Electronic Engineering, Dec 2017, vol. 13, no. 4, pp. 362-373.

[12] N. Boules, "Prediction of No-load Flux Density Distribution Permanent Magnet Machines", IEEE Trans. on Ind. Appl. May 1985 , no. 3, pp. 633-643.

[13] B. Ackermann and R. Sottek, "Analytical Modeling of the Cogging Torque Permanent Magnet Motors", Electrical Engineering (Archiv fur Elektrotechnik), Mar 1995, vol. 78 no. 2, pp. $117-125$.

14] A. Radun, "Analytical Calculation of the Switched Reluctance Motor's Unaligned Inductance", IEEE Trans. on Mag. Nov 1999, vol. 35 , no. 6 , pp. $4473-4481$.

15] K. F. Rasmussen, J. H. Davies, T. J. Miller, M. I. McGelp and M. Olaru, "Analytical and Numerical Computation of Air-Gap Magnetic Fields Brushless Motors with Surface Permanent Magnets", IEEE Trans. on Ind. Appl. Nov 2000, vol. 36, no. 6, pp. $1547-1554$.

[16] X. Wang, Q. Li, S, . Wang and Q. Li, "Analytical Calculation of Air-Gap Magnetic Field Distribution and Instantaneous Characteristics of Brushless DC Motors", IEEE Trans. on energy conversion, Sep 2003, vol. 18, no. 3, pp. 424-432.

[17] Z. J. Liu and J. T. Li, "Analytical Solution of Air-Gap Field Permanent-Magnet Motors Taking into Account the Effect of Pole Transition over Slots", IEEE Trans. on Mag. Oct 2007, vol. 43 , no. 10 , pp. $3872-3883$.

[18] Z. J. Liu, J. T. Li and Q. Jiang, "An Improved Analytical Solution for Predicting Magnetic Forces Permanent Magnet Motors", J. of Appl. Phys. Apr 2008, vol. 103, no. 7, 07F135.

19] Liu, ZJ, Li and JT, "Accurate Prediction of Magnetic Field and Magnetic Forces Permanent Magnet Motors using an Analytical Solution", IEEE Trans. on Energy Conversion. Sep 2008, vol. 23, no. 3 , pp. $717-726$.

[20] T. Lubin, S. Mezani and A. Rezzoug, "Exact Analytical Method for Magnetic Field Computation the Air Gap of Cylindrical Electrical Machines Considering Slotting Effects", IEEE Trans. on Mag. Apr 2010, vol. 46, no. 4, pp. 1092-1099.

21] B. L. Gysen, E. Ilhan, K. J. Meessen, J. J. Paulides and E. A. Lomonova, "Modeling of Flux Switching Permanent Magnet Machines with Fourier Analysis", IEEE Trans. on Mag. June 2010, vol. 46, no. 6, pp. 1499-1502.

[22] K. Boughrara, R. Ibtiouen and T. Lubin, "Analytical Prediction of Magnetic Field Parallel Double Excitation and Spoke-Type Permanent-Magnet Machines Accounting for Tooth-Tips and Shape of Polar Pieces", IEEE Trans. on Mag. July 2012, vol. 48, no. 7, pp. 2121-2137.

[23] K. Boughrara, T. Lubin and R. Ibtiouen, "General Subdomain Model for Predicting Magnetic Field Internal and External Rotor Multiphase Flux-Switching Machines Topologies", IEEE Trans. on Mag. Oct 2013, vol. 49, no. 10, pp. 5310-5325.

$24]$ T. L. Tiang, D. Ishak and M. K. Jamil, "Complete Subdomain Model for Surface-Mounted Permanent Magnet Machines", Energy Conversion CENCON, 2014 IEEE Conference, 2014 Oct 13, pp. $140-145$.

25] X. Liu, H. Hu, J. Zhao, A. Belahcen, L. Tang and L. Yang, "Analytical Solution of the Magnetic Field and EMF Calculation Ironless BLDC Motor", IEEE Trans.on Mag. Feb 2016, vol. 52, no. 2, pp. 1-0.

26] B. Dianati, H. Heydari and S. A. Afsari, "Analytical Computation of Air-Gap Magnetic Field a Viable Superconductive Magnetic Gear", IEEE Trans. on Appl. Superconductivity. Sep 2016, vol. 26 , no. 6 , pp. $1-2$.

27] F. M. Sargos and A. Rezzoug, "Analytical Calculation of Airgap Magnetic Field Produced by Inset Permanent Magnet Rotor Machine", J. Physics III. 1990, 1, pp. 103-110. 
[28] Z. Q. Zhu, D. Howe and Z. P. Xia, "Prediction of Open-Circuit Received 17 June 2017 Airgap Field Distribution Brushless Machines having an Inset Permanent Magnet Rotor Topology", IEEE Trans. on Mag. Jan 1994, vol. 30, no. 1, pp. 98-107.

[29] A. Rahideh and T. Korakianitis, "Analytical Magnetic Field Distribution of Slotless Brushless Machines with Inset Permanent Magnets", IEEE Trans. on Mag. June 2011, vol. 47, no. 6, pp. $1763-1774$.

[30] T. Lubin, S. Mezani and A. Rezzoug, "Two-Dimensional Analytical Calculation of Magnetic Field and Electromagnetic Torque for Surface-Inset Permanent-Magnet Motors", IEEE Trans.on Mag. June 2012, vol. 48, no. 6, pp. 2080-2091.

Ali Jabbari is an assistant professor in Mechanical Engineering Department at Arak University, Arak, Iran. He obtained a BSc degree in Mechanical Engineering from Iran University of Science and Technology in 2002. He received his MSc and $\mathrm{PhD}$ degrees both in Mechanical engineering from Mazandran University in 2004 and 2009, respectively. His research interests include renewable energy, electric machines, mechatronic systems and metal forming. 